\title{
CONTO MISSA DO GALO: LENDO E INTERPRETANDO O REALISMO DO SÉCULO XIX
}

\section{William Campos da Silva}

Um grande conto escrito por um grande homem, lembrado por muitos como o maior escritor brasileiro de todos, A Missa do Galo, conto escrito em I893 por Machado de Assis, um conto que mesmo escrito no final do século XIX, ainda é muito atual no começo do século XXI, a obra realista trata de um assunto muito debatido e escrito na época, o adultério dentro da família brasileira da época, de uma forma muito inteligente que também é abordado em outros trabalhos do autor como Dom Casmurro, Memórias Póstumas de Brás Cubas entre outros, a obra está dentro da chamada "segunda fase" de Machado de Assis, ou seja sua fase como escritor realista, os contos escritos nessa época e principalmente os mais famosos, como a Missa do Galo, são conhecidos como contos escritos na época madura de Machado, quando o autor já está com suas famosas técnicas de escrita muito bem alinhadas e não está mais escrevendo de maneira romântica como em sua "primeira fase" onde era mais novo. Para descrever melhor essa fase tão importante de Machado, o escritor Roberto Schwarz faz uma descrição do tipo de escrita e narração existente dentro de Memórias Póstumas de Brás Cubas, o livro que abre as portas do realismo nacional.

\begin{abstract}
Ao colocar na posição de sujeito narrativo o tipo social de Brás Cubas - o verdadeiro alvo da sátira - Machado tomava um rumo perverso e desnorteante. Camuflada pela primeira pessoa do singular, que a ninguém ocorreria usar em prejuízo próprio e com propósito infamante, a imitação ferina dos comportamentos da elite criava um quadro de alta mistificação: cabe ao leitor descobrir que não está diante de um exemplo de auto-exame e requintada franqueza, mas de uma denúncia devastadora. (SCHWARZ, 1990, p. I19)
\end{abstract}

Entrando então na obra Missa do Galo o conto é narrado por Nogueira nosso personagem principal, que ao narrar a história já está velho e lembrando de um episódio

\footnotetext{
${ }^{\mathrm{I}}$ Licenciando em Letras Português/Inglês na Universidade Regional de Blumenau -FURB. E-mail: wellingtonff@hotmail.com.
} 
muito marcante de sua adolescência, sabemos que o narrador pode estar mais velho com indícios dentro do texto como quando Nogueira não se lembra da data em que tudo aconteceu e diz que fora em meados de 186I ou I862. Nogueira vai ao Rio de Janeiro capital para realizar seus estudos preparatórios e fica hospedado na casa do escrivão Meneses, que fora casado com sua prima, mas agora é casado com Conceição, uma mulher que aos primeiros olhos não chama atenção de Nogueira e é descrita como uma mulher normal, nem feia nem bonita, nessa descrição em específico Conceição começa a chamar mais atenção do leitor pois não é uma descrição tão comum

Ao Nogueira continuar sua história, temos a descrição da família que vivia na casa e essa descrição parece algo normal “ A família era pequena, o escrivão, a mulher, a sogra e duas escravas. Costumes velhos. Às dez horas da noite toda a gente estava nos quartos; às dez e meia a casa dormia” Machado nas entrelinhas tenta montar ao leitor a velha e normal família brasileira, com escravos, um marido uma mulher, e ao falar do horário de dormir, tenta trazer ao leitor como é monótono a vida em família, tentando tirar essa romanização da instituição família, algo comum entre os escritores realista e naturalista, ir contra as bases do país, como religião, escravatura, a família brasileira, algo totalmente contrário ao romantismo. A cartada principal do conto vem logo após quando Nogueira fica intrigado com as constantes idas de Meneses ao teatro e como nunca houvera ido a tal espetáculo, pede para ir com Meneses, então junto a algumas caretas da sogra, as risadas das escravas e com Meneses não respondendo apenas se vestindo e indo embora, descobrimos que Meneses, trai Conceição todas as semanas indo ao "teatro" e passando a noite fora, Conceição por sua vez mesmo sabendo dessa traição aceita, pois sabe que se separar do marido não terá para onde ir, e ela e sua mãe serão largadas a sorte nas ruas da capital. Na noite de véspera de Natal, o escrivão decide passar o dia no teatro largando a própria família para comemorar o aniversário de Jesus ao lado de sua amante, nos tempos atuais temos uma noção de dia de natal muito diferente do final do século XIX, época ainda muito longe ainda do consumismo desenfreado da atualidade o feriado tinha uma principal importância religiosa, que não importa quanto tempo passe ainda será o verdadeiro significado do natal sendo uma festa cristã que comemora justamente o nascimento do salvador e filho do criador, temos nesse sentido então a primeira desconstrução de Machado no conto para com as bases do governo. 
Nogueira vai à primeira sala da casa onde ficará lendo e esperando a hora passar para poder ver a missa do galo no centro da cidade, evento que nosso protagonista nunca assistiu e não irá desperdiçar essa chance estando na Capital do país e podendo ver de perto o que provavelmente era a maior e mais importante missa do galo realizada no país, então após as dez horas quando toda a família já estava deitada tinha como companheiro o romance de Alexandre Dumas, os três mosqueteiros para lhe fazer companhia. Conceição acorda em meio à noite e vai até onde Nogueira está, Conceição pergunta a nogueira se ele gosta de romances ao ver o livro que outrora estava aberto em sua frente e esse é o primeiro sinal das sugestões de desejo e erotismo que acontece entre os personagens, Nogueira responde que sim para a pergunta e Conceição o pergunta se ele já leu a moreninha e com essa simples pergunta podemos ter diversas ideias, a moreninha de Joaquim Manuel de Macedo, é popularmente conhecida como o primeiro romance romântico brasileiro, e então vem a crítica de machado ao romantismo, como muito autores realistas, um forma de ataque ao romantismo era fazer personagens femininas de suas obras lerem romances românticos, e essas personagens geralmente eram quem cometiam algo socialmente não aceito e acabam com o casamento, assim como em O primo Basílio ou Madame Bovary, fazer essas personagens lerem romances era mostrar como mulheres que cometiam algo liam romances e enchiam duas cabeças de bobagens e assim tinham desejos que não eram certos, e podemos pressupor que Conceição é uma dessas mulheres.

Machado começa a mexer cada vez mais com o erotismo, ao longo da conversa entre os dois personagens, e quando o assunto ficava bom e o narrador se empolgada vinha a frase “mais baixo, mamãe pode acordar!", mostrando assim o clima de perigo que os personagens corriam, como se os dois estivessem juntos em um quarto, e uma mulher casada não seria vista com bons olhos conversando com uma jovem tarde da noite em sua casa. Machado não explora a sexualidade com toques, e sim a sexualidade da mente humana com suas vontades e desejos escondidos que não são aceitos socialmente, ao longo da conversa podemos notar o controle da situação por Conceição e a falta de experiência e os desejos a flor da pele de Nogueira que na época tinha apenas dezessete anos, Conceição começa a se transformar aos olhos de Nogueira a mulher com um rosto mediano, começa a ficar linda, lindíssima, seus olhos não conseguem para de notar o balanço do corpo, "o bico das chinelas" que podemos 
entender como os peitos de Conceição sem sutiã apenas apoiados em seu roupão. Machado derruba mais um pilar do governo que é a religião, transformando aos olhos de Nogueira a "Santa" Conceição em uma mulher extremamente sensual, provocante e tudo isso a apenas alguns centímetros dele e sempre que o narrador se animava, vinha a frase "mais baixo, mamãe pode acordar! ", sempre lembrando que ao mesmo tempo de que o que estava acontecendo ali era apenas uma conversa, nas entrelinhas era algo proibido que ia contra a religião e os costumes da sociedade.

Em uma recordação de Nogueira da noite ele diz sobre um momento onde eles conversavam sobre quadros que estavam na parede, de mulher vulgares que segundo conceição ficariam melhores em uma casa de barbeiro, onde os homens conversavam sobre mulheres e namoros e suas vistas eram agraciadas com quadros de mulheres bonitas, nesse momento Machado nos mostra um ponto da sociedade onde existem uma divisão onde é certo os homens falarem sobre mulheres e esse lugar não é a própria casa, onde está a sua família, a imagem da Missa retorna a Nogueira que àquela hora graças a Conceição já tinha esquecido que logo teria de ir à Missa do Galo, Nogueira estava em sono Magnético que lê tolhia a linha e os sentidos, ao final da conversa Conceição falava sobre sua vida passada, sobre suas preocupações quando mais jovens, ao terminar de contar olha para as paredes e diz que precisa trocar o papel de parede, essa frase se faz lembrar da Sra. Bovary, que para reprimir o tédio de ficar em casa todos os dias, mudava as mobílias, cortinas e tapetes.

A conversa entre os personagens termina com o vizinho aos berros na janela gritando “Missa do Galo, Missa do Galo” para chamar Nogueira a meia noite, como já era combinado, as horas se passaram muito rápido e ao final quando Nogueira vai embora e chegado a missa, não conseguia para de pensar em Conceição e das conversas que noite adentro tiveram, no dia seguindo Conceição agiu como se nada tivesse acontecido e Nogueira apenas repetiu, tempos depois ao voltar ao Rio de Janeiro, Nogueira descobre que o velho escrivão houvera morrido e que Conceição tinha casado com o escrevente juramentado do marido.

A beleza do conto está no que aconteceu, ou melhor dizendo, no que não aconteceu, o desejo e sexualidade impostos na conversa não chegaram a famosa cena de alcova, Machado prefere as entrelinhas, fazer o leitor pensar e imaginar, misturando em um simples diálogo de uma noite, o moral e o imoral, o sagrado e o pecado, a vontade e a proibição, o 
desejo carnal de duas pessoas e o respeito moral com a sociedade, o quando essas vontade se misturam, mesmo em todo o diálogo o único toque fora um toque de Conceição no ombro de Nogueira, bastou apenas as entrelinhas para tornar esse um dos contos mais inesquecíveis de Machado de Assis.

\section{REFERÊNCIAS}

ASSIS, Machado. Missa do galo. In: ASSIS, Machado de. 50 Contos de Machado de Assis: selecionados por john gledson. São Paulo: Companhia das Letras, 2007. p. 496

SCHWARZ, Roberto. Um mestre na periferia do capitalismo - Machado de Assis. São Paulo: Duas Cidades, I990, I5I $\mathrm{p}$

TV, Literatus. Leitura Ouvida \# 4 - Missa do Galo (Machado de Assis). 2017. (I7mios). Disponível em: 〈https://www.youtube.com/watch?v=d8zOFMLEj94\&t=21s $>$. Acesso em: I4 maio. 2020. 